\title{
Novel Set of Sex-Specific PCR-Based Markers Reveals New Hypothesis of Sex Differentiation in Date Palm
}

\author{
Atia A. M. Mohamed*, Adawy S. Sami \\ Genome Mapping Dept., Agricultural Genetic Engineering Research Institute (AGERI), ARC, Giza, Egypt
}

Email address:

matia@ageri.sci.eg (A. A. M. Mohamed), samiadawy@yahoo.com (A. S. Sami)

To cite this article:

Atia A. M. Mohamed, Adawy S. Sami. Novel Set of Sex-Specific PCR-Based Markers Reveals New Hypothesis of Sex Differentiation in Date Palm. Journal of Plant Sciences. Vol. 3, No. 3, 2015, pp. 150-161. doi: 10.11648/j.jps.20150303.16

\begin{abstract}
The date palm (Phoenix dactylifera $\mathrm{L}$.), $2 \mathrm{n}=36$, is a dioecious long-lived monocotyledonous plant, with separate male and female trees. The dioecy represents the major challenge in development of breeding programs as it is impossible to distinguish tree gander till they flower approximately five to eight years after planting. Although, during the past two decades numerous attempts to develop molecular markers can discriminate among male and female trees in date palm. But, to date, sex-differentiation mechanism is still uncertain and there is no reliable way to determine the sex of date palm plants before reproductive age across all cultivars. Here, we employed an effective three novel gene-targeting marker approaches (SCoT, CDDP and ITAP) in additions to AFLP, in an attempt to develop a novel set of reliable sex-specific PCR-based markers can helping in early gender determination in Egyptian date palm trees. A set of 26 SCoT, 21 CDDP, 18 ITAP and 14 AFLP primers/primer combinations (PCs) were applied against twelve date palm genotypes belonging to three superior Egyptian date palm cultivars to identify any sex-specific markers. Four SCoT (SCoT1, SCoT24, SCoT26 and SCoT35), two CDDP (CDDP4 and CDDP6), one ITAP (ITAP-8/1) and one AFLP (AFLP-4/1) primer/PC exhibited differential fragments/bands between males and females. These differential bands were gel extracted and cloned for subsequent sequencing analysis. Three of the sequenced bands found to be contain more than one sequence. BLAST analysis results indicated that the eleven sequences generated from different gene-targeting marker systems (SCoT, CDDP and ITAP) revealed main similarity with master transcription factors, transcriptional activators/repressors and regulatory proteins involved in plant hormone signal transduction pathways, plant development and biosynthesis of secondary metabolites, playing important role in different types of abiotic and biotic stresses in date palm or oil palm. We speculate that kind of similarity is not just a coincidence. Our results reveals hypothesis that sex differentiation is a complex but well-organized process that involves endogenous and exogenous factors regulate and control the changes in gene expression, physiology, metabolism and architecture of the plant. These results represent the first case-study focusing on the applications of CDDP, ITAP and SCoT techniques as a novel gene targeting markers in sex-determination in date palm. Moreover, indicate that sex-differentiation process have to be addressed at system biology level for deep and better understanding. This developed sex-specific markers expected to be helpful in distinguish the gander in date palm at earliest stages.
\end{abstract}

Keywords: Date Palm, Sex-Differentiation, SCoT, CDDP, ITAP

\section{Introduction}

Date palm (Phoenix dactylifera $\mathrm{L} ., 2 \mathrm{n}=2 \mathrm{x}=36$ ) is a dioecious, perennial, monocotyledonous fruit tree that belongs to the family Arecaceae. Date palm has been cultivated for at least 7,000 years and is believed to have originated in Mesopotamia [1]. The date palm trees are cultivated not only for their valuable fruits (dates), but also for producing fuel, fiber and as shelter for ground crops. Therefore, it has a major socioeconomic importance especially in the Middle East, North Africa and to a small extent in California and Mexico. The tree plays an important role in the development of sustainable agriculture in many drought and saline-affected regions of the world [2, 3].

Date palm is an important economic crop in Egypt where the world's largest producer over the last two years is Egypt with $1,470,000 \mathrm{mt}$ followed by Islamic Republic of Iran 
$(1,066,000 \mathrm{mt})$ and Saudi Arabia (1,050,000 mt) [4].

In date palm, long juvenility and dioecy presents a challenge in their breeding programs because it is impossible to distinguish trees gander until they flower approximately 5 to 8 years after planting [5]. The conventional techniques such as the morphological screening could be applicable, but particularly when the fruits are ripe.

Date palm species is commonly propagated by offshoots and by seeds. For both approaches, extremely slow growth of seedlings and offshoots does not allow the use of classical breeding techniques; it takes 8-10 years before plants produce fruit. Moreover, healthy date palm tree usually not producing more than 10-40 offshoots during its lifetime (depending on the cultivar and the environmental conditions). Although, seed germination is the easiest but seedlings may take up to 10 years before flowering and fruiting. Usually the progeny derived from seeds are heterozygote and do not carry the same mother characters. Moreover, offspring from seeds are approximately equally split between males and females; however, many fewer male plants as pollen donors are generally required as compared with female plants (one male is used to hand pollinate about 90-100 females) [6].

During last decades, serious efforts have been paid in an attempt to understanding the basis of sex determination/ differentiation in date palm and to develop methods can identifying the gender at an early stage. This studies included the uses of isozymes [7], peroxydases [8], molecular marker tool such random amplified polymorphic DNA (RAPD) [9, 10], PCR-based restriction fragment length polymorphism (PCR-RFLP) approach [11], microsatellites [12], and recently; PCR-based approaches (RAPD and SCoT) [13].

In this paper, for the first time, we employed different molecular marker systems including a novel gene-targeting marker approaches; Conserved DNA-Derived Polymorphism (CDDP), Start Codon Targeted Polymorphism (SCoT) and Intron-Targeted Amplified Polymorphism (ITAP), in additions to Amplified Fragment Length Polymorphism (AFLP), in an attempt to develop a novel set of sex-specific PCR-based markers can helping in early gender determination in Egyptian date palm trees.

\section{Materials and Methods}

\subsection{Plant Material}

Twelve samples representing the male and female of three Egyptian cultivars (two plants from each gender) were subjected to molecular analysis. Two additional samples were prepared to represent bulked males and bulked females.

High-quality genomic DNA was extracted from fresh leaves $(100 \mathrm{mg})$ of all collected plants using a DNeasy Plant Mini Kit (QIAGEN, Santa Clarita, CA) and according to the manufacturer's protocol. The DNA was quantified with NanoDrop Spectrophotometer (Thermo Fisher Scientific Inc.).
All samples were adjusted to a concentration of $10 \mathrm{ng} / \mu \mathrm{l}$ for subsequent analyses.

\subsection{Start Codon Targeted Polymorphism (SCoT) Analysis}

SCoT-PCR was performed as described by [13]. A new set of 26 18-mer primers (Not the same set used by [13]) were used against the twelve date palm samples in addition to the two bulks in order to identify any sex-specific markers.

\subsection{Conserved DNA-Derived Polymorphism (CDDP) Analysis}

A total of 21 CDDP primers were tested against the twelve date palm samples and two bulks. These primers were originally developed by [14]. PCR reaction was performed also as described by [14].

\subsection{Intron-Targeted Amplified Polymorphism (ITAP) Analysis}

A total of 18 ITAP primer combinations were tested against the twelve date palm samples and two bulks. These primer combinations were originally developed by [15]. PCR reaction was performed as described by [15].

\subsection{Amplified Fragment Length Polymorphism (AFLP) Analysis}

The AFLP analysis was performed using the AFLP $\AA$ Analysis System II (Invitrogen, USA) as described by [16]. Among 24 AFLP primer combinations (PCs) were initially tested on male and female samples, the best fourteen PCs were chosen on the basis of the number of bands, clarity of pattern, and distribution on the gel. These were tested again on the twelve date palm samples in addition to the two bulks.

\subsection{Cloning of the PCR Product and Transformation}

The fragments that exhibited differential pattern between males and females in following marker techniques (SCoT, CDDP and ITAP) were extracted from agarose gel using QIAquick Gel Extraction Kit (QIAGEN, Santa Clarita, CA) or from polyacrylamide gel (AFLP) according to [17]. Then the purified PCR products were cloned to $\mathrm{pGEM} \AA$ - T Easy Vector System (Promega) according to the manufacturer's instructions and transformed to DH5-alpha E. coli competent cells for subsequent sequencing analysis.

Positive transformants/colonies were verified using PCR approach. Then plasmid miniprep was performed of positive clones to harvest the vectors potentially with insert using QIAprep ${ }^{\circledR}$ Miniprep purification kit (QIAGEN, Santa Clarita, CA).

\subsection{DNA Sequencing and Data Analysis}

Sequencing of candidates of pGEM ${ }^{\circledR}-\mathrm{T}$ Easy Vector with SCoTs, CDDPs, ITAPs and AFLPs inserts were accomplished with an ABI310 DNA sequencer (Applied Biosystems, Norwalk, Conn.) by using synthetic primer complementary to the vector sequences flanking the multiple cloning sites (M13 
forward primer). To confirm that each differential band/amplicons not containing more than one sequence with the same molecular size; eight verified positive clones were subjected for DNA sequencing analysis.

The sequence reads were aligned, using ClustalW multiple sequence alignment algorithm [18], against the Qatari date palm genome. BLAST analysis [19] was used to identify the regions among the reads that were not well aligned with the reference sequence (or the vector backbone) by an NCBI DNA sequence database search. A homology search was performed using BLASTX against the NCBI protein database (http://www.ncbi.nlm.nih.gov).

\section{Results}

\subsection{Molecular Markers Analysis}

Out of seventy-nine primers and/or PCs representing three gene targeting marker types (26 SCoT, 21 CDDP and 18 ITAP) in addition to 14 AFLP PCs, were applied against the fourteen date palm samples; four SCoT primers (SCoT1, SCoT24, SCoT26 and SCoT35), two CDDP primers (CDDP4 and CDDP6), one ITAP PC (ITAP-8/1) and one AFLP PC (AFLP-4/1) successfully revealed a differential amplicons can clearly distinguish between fourteen male and female samples belonging to the three Egyptian date palm cultivars (Fig. 1).

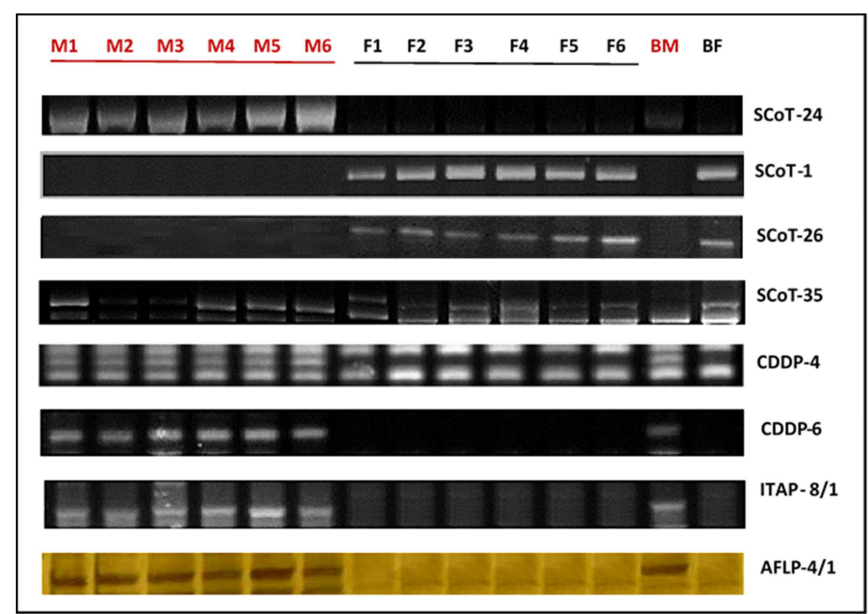

Figure 1. The differential amplicons pattern generated from SCOT, CDDP, ITAP and AFLP marker types showing their power to distinguish between male and female samples belonging to the three Egyptian date palm cultivars. Samples: $1 M=$ male Zaghloul-1, 2M= male Zaghloul-2, 3M= male Hayani-1, 4M= male Hayani-2, 5M= male Samany-1, 6M= male Samany-2, $1 F=$ female Zaghloul-1, $2 F=$ female Zaghloul-2, $3 F=$ female Hayani- $1,4 F=$ female Hayani-2, $5 F=$ female Samany- 1 and $6 F=$ female Samany-2. $B M=$ Bulk of males and $B F=$ Bulk of females.

\subsection{Sequencing Data Analysis}

In order to identify if the amplicons differentially isolated from different marker types (SCoT, CDDP, ITAP and AFLP) carry one or more than one sequence, eight verified positive colonies were selected randomly for sequencing. The vector sequence was initially removed from all generated sequences. Then, local sequence alignment was done using ClustalW software, which showed that the differentially isolated amplicons/fragments (SCoT1, SCoT24, CDDP4, ITAP-8/1 and AFLP-4/1) contain only one sequence per amplicons/fragment. While, SCoT26 and CDDP6 differential isolated amplicons contains two sequences per each amplicon/fragment. Meanwhile, SCoT35 differentially isolated amplicon contain three different sequences per amplicon/fragment.

The best way to identify and characterize an unknown sequence is to see if that sequence already exists in a public database (Genbank). MegaBLAST, discontiguous-MegaBLAST, and BLASTn web-tools were used to accomplish this goal. Moreover, the sequences were also subjected to the BLASTx analysis which compares translational products of the nucleotide query sequence to a protein databases. The BLASTn analysis results generally indicated that eleven sequences generated from different gene-targeting marker systems (SCoT, CDDP and ITAP) revealed medium to high degree of similarity with well-defined sequences/genes in date palm or oil palm genomes (Table 1). On the other hand, the BLASTn analysis result of the sequence generated from AFLP revealed no similarity with any gene/protein in date palm or oil palm genomes.

The BLAST results of SCoT sequences against genbank database revealed that SCoT-1 showed high degree of similarity $(99 \%)$ and query coverage $(82 \%)$ with shikimate O-hydroxycinnamoyl-transferase-like in date palm (Phoenix dactylifera). While, SCoT24 showed good degree of similarity (58\%) and high query coverage (91\%) with probable indole-3-acetic acid-amido synthetase GH3.8 in oil palm (Elaeis guineensis). Whilst, SCoT26 which carry two different sequences; SCoT26-1 showed high degree of similarity (98\%) and query coverage (97\%) with cysteine-rich repeat secretory protein 38-like and SCoT26-2 showed good degree of similarity (50\%) and high query coverage $(100 \%)$ with zinc finger protein 1-like in date palm. Whereas, SCoT35 which carry three different sequences; SCoT35-1 showed good degree of similarity (55\%) and high query coverage (99\%) with trihelix transcription factor GTL1-like, SCoT35-3 showed high degree of similarity (88\%) and query coverage (99\%) with probable methyltransferase PMT28, and SCoT35-5 showed good degree of similarity (35\%) and high query coverage $(97 \%)$ with probable WRKY transcription factor 65 in date palm genome (Table 1).

The total number of generated sex-specific markers from all marker types was twelve markers; six markers (50\%) were male-specific markers (SCoT1, CDDP4, CDDP6-1, CDDP6-2, ITAP-8/1 and AFLP-4/1) and six markers (50\%) were femalespecific markers (SCoT24, SCoT26-1, SCoT26-2, SCoT35-1, SCoT35-3 and SCoT35-5) (Table 1). 
Table 1. Primer code, product length, sex linked, BLASTn (query cover, E-value and identity), BLASTx (query cover, E-value and identity), gene/protein hit and KEGG ID or NCBI- GeneID of all differentially sequenced fragments generated from different marker systems (SCoT, CDDP, ITAP and AFLP) distinguishing between males and females in belonging to three Egyptian date palm cultivars.

\begin{tabular}{|c|c|c|c|c|c|c|c|c|c|c|}
\hline \multirow[b]{2}{*}{$\begin{array}{l}\text { Primer } \\
\text { Code }\end{array}$} & \multirow{2}{*}{$\begin{array}{l}\text { Product } \\
\text { Length } \\
\text { (bp) }\end{array}$} & \multirow{2}{*}{$\begin{array}{c}\text { Sex } \\
\text { linked }\end{array}$} & \multicolumn{3}{|c|}{ BLASTn } & \multicolumn{3}{|c|}{ BLASTx } & \multirow[b]{2}{*}{ Gene/Protein Hit } & \multirow{2}{*}{$\begin{array}{c}\text { KEGG ID } \\
\text { or NCBI- } \\
\text { Gene ID }\end{array}$} \\
\hline & & & $\begin{array}{l}\text { Query } \\
\text { Cover }\end{array}$ & E value & Identity & $\begin{array}{l}\text { Query } \\
\text { Cover }\end{array}$ & E value & Identity & & \\
\hline SCoT1 & 553 & M & $82 \%$ & 0.0 & $99 \%$ & $82 \%$ & $5 e-99$ & $98 \%$ & $\begin{array}{l}\text { Shikimate O-hydroxycinnamoyl- } \\
\text { transferase-like [Phoenix dactylifera] }\end{array}$ & K13065 \\
\hline SCoT24 & 699 & $\mathrm{~F}$ & $58 \%$ & $2 \mathrm{e}-165$ & $91 \%$ & $47 \%$ & $2 e-59$ & $93 \%$ & $\begin{array}{l}\text { Probable indole-3-acetic acid-amido } \\
\text { synthetase GH3.8 [Elaeis guineensis] }\end{array}$ & K14487 \\
\hline SCoT26-1 & 597 & $\mathrm{~F}$ & $98 \%$ & 0.0 & $97 \%$ & $76 \%$ & $5 e-87$ & $93 \%$ & $\begin{array}{l}\text { Cysteine-rich repeat secretory protein } \\
\text { 38-like [Phoenix dactylifera] }\end{array}$ & 103696165 \\
\hline SCoT26-2 & 1245 & $\mathrm{~F}$ & $50 \%$ & 0.0 & $100 \%$ & $50 \%$ & $2 e-85$ & $100 \%$ & $\begin{array}{l}\text { Zinc finger protein 1-like } \\
{[\text { Phoenix dactylifera }]}\end{array}$ & 103719020 \\
\hline SCoT35-1 & 1550 & $\mathrm{~F}$ & $55 \%$ & 0.0 & $99 \%$ & $52 \%$ & $8 \mathrm{e}-128$ & $85 \%$ & $\begin{array}{l}\text { Trihelix transcription factor GTL1-like } \\
\text { [Phoenix dactylifera] }\end{array}$ & 103718752 \\
\hline SCoT35-3 & 586 & $\mathrm{~F}$ & $88 \%$ & 0.0 & $99 \%$ & $79 \%$ & $3 e-18$ & $99 \%$ & $\begin{array}{l}\text { Probable methyltransferase } \\
\text { PMT28 [ Phoenix dactylifera] }\end{array}$ & 103702721 \\
\hline SCoT35-5 & 1420 & $\mathrm{~F}$ & $35 \%$ & $2 \mathrm{e}-120$ & $97 \%$ & $22 \%$ & $1 \mathrm{e}-08$ & $67 \%$ & $\begin{array}{l}\text { Probable WRKY transcription factor } 65 \\
{[\text { Phoenix dactylifera }]}\end{array}$ & 103713754 \\
\hline CDDP-4 & 195 & M & $40 \%$ & $8 e-32$ & $100 \%$ & - & - & - & $\begin{array}{l}\text { Ethylene-responsive transcription factor } \\
\text { 4-like [ Phoenix dactylifera] }\end{array}$ & 103705587 \\
\hline CDDP-6-1 & 605 & M & $23 \%$ & $5 e-39$ & $89 \%$ & - & - & - & $\begin{array}{l}\text { Phosphoenolpyruvate/phosphate trans- } \\
\text { locator 1 (PPT1) [Phoenix dactylifera] }\end{array}$ & 103708170 \\
\hline CDDP-6-2 & 608 & M & $60 \%$ & $6 e-26$ & $68 \%$ & - & - & - & $\begin{array}{l}\text { Regulatory protein NPR1-like } \\
\text { [Elaeis guineensis] }\end{array}$ & K14508 \\
\hline ITAP-8/1 & 731 & M & $20 \%$ & $4 e-16$ & $80 \%$ & - & - & - & $\begin{array}{l}\text { Eukaryotic translation initiation factor } \\
\text { 4E-1-like [ Phoenix dactylifera] }\end{array}$ & K03259 \\
\hline AFLP- $4 / 2$ & 240 & M & $97 \%$ & 1e-109 & $99 \%$ & - & - & - & $\begin{array}{l}\text { Uncharacterized LOC } 103710036 \\
{[\text { Phoenix dactylifera] }}\end{array}$ & - \\
\hline
\end{tabular}

The above results generally indicated that the eleven sequences generated from different gene-targeting marker systems (SCoT, CDDP and ITAP) revealed mainly medium to high degree of similarity with transcription factors, transcriptional activators/repressors and regulatory proteins involved in plant hormone signal transduction pathways, plant development and biosynthesis of secondary metabolites playing important role in different types of abiotic and biotic stresses in date palm or oil palm.

The role for each gene/protein from those showed high similarity with our differentially sequenced markers in plant development or abiotic and biotic stresses resistance/tolerance will be discussed in details later.

\section{Discussion}

Early sex identification of female date palm trees (which produce dates) would allow new breeding approaches via controlled crossings and facilitate marker-assisted selection (MAS). For these reasons, sex-linked markers have been sought in date palm for decades [20].

\subsection{Previous Identification of Sex-linked Markers in Date Palm}

Nowadays, [21] developed the first male-specific cytogenetic marker using fluorescence in situ hybridization (FISH) localization of 45S rDNA in Egyptian date palm trees (cv. Zaghloul and Siwi). Recently, [13] employed for the first time SCoT technique as gene-targeting marker system in addition to RAPD to identify any sex-linked markers in
Egyptian date palm. They identified two SCoT and four RAPD sex-specific markers. While, [12] employed the microsatellites marker system for the first time to identify three male-specific SSR markers tested on date palm genotypes collected from different geographic origin (Tunisia, Morocco, Italy, Djibouti, Oman, Syria and Iraq) with clearly ignoring for Egyptian genotypes (which produce about 20\% of global dates). While, [11] identified male-linked markers, but this markers still requires confirmation, as the markers were validated only in a small sample and with an unsatisfactory accuracy of $90 \%$ [12].

\subsection{Utility of Gene-targeting Marker Systems}

On the basis of the characterization of plant genes and gene families, new methods have been developed to analyze genetic diversity based on genomic database mining.

Following this, many recent studies have suggested that polymorphism in functional regions of the genome should be exploited to achieve better estimates of genetic relationships that are relevant to plant breeding or germplasm conservation $[22,23]$.

In 2009, Collard \& Mackill developed two gene-targeting marker systems called: start codon targeted polymorphism (SCoT) and conserved DNA derived polymorphism (CDDP). This markers uses single short primers to generate useful genetic markers across functional domains of well-characterized plant genes $[13,14]$. Another recently developed technique, Intron-Targeted Amplified Polymorphism (ITAP), is based on the fact that intron sequences are generally less conserved than exons, and 
display polymorphism due to length and/or nucleotide variation in their alleles. Primers designed to anneal in conserved exons to amplify across introns can show length polymorphism in the targeted intron [24]. These markers may provide valuable new tools for genetic diversity assessment of germplasm collections as well as in other fields of plant science and breeding. However, the utility of these markers has yet to be thoroughly addressed.

The employment of these markers systems in sex determination studies in dioecious plants represent a new challenge to investigate the powerful for these type of markers in such studies. Our results confirm that the three marker systems; SCoT, CDDP and IT markers are suitable for characterizing and differentiating between the two ganders in date palm and that they can possibly also used in other dioecious plants, alone or in combinations. The successful transferability and cross-species amplification of IT markers may result from the relative conservation of exon-intron junctions and gene structures across plants.

Moreover, it is also possible to tag resistance mechanism-related genes with the CDDP and ITAP systems because both systems use primers based on allele sequences of functionally characterized genes, and thus specific banding patterns corresponding to plant phenotypes can be identified. Across functional domains of well characterized plant genes these short tags can then generate informative banding patterns that have many uses, e.g., germplasm genetic diversity assessment, or mapping and trait association studies [24, 25].

\subsection{Understanding of Developmental Biology in Plant}

In all complex organisms, specific transcriptional programs are required for proper developmental patterning and to ensure appropriate responses to any changes in environmental conditions and stresses. During development, the expression of developmental genes is often tightly controlled to be within particular levels and to only occur in certain cells irrespective of changes in environmental conditions. In general, gene regulation is not a linear one-to-one process, but rather occurs in the context of complex networks of interactions between multiple genes and multiple transcription factors (TFs). For instance, the TFs that control the expression of a gene often act together with other TFs. Furthermore, TFs are themselves extensively regulated.

Indeed, the transition from vegetative growth to reproductive development is a complex but well-organized process that involves changes in gene expression, physiology, metabolism and architecture of the plant [26]. The transition between these developmental programmes is executed through a change in the nature of the shoot apical meristem, transforming leaf-into-flower-type primordial [27, 28]. These events are tightly regulated and the resulting onset of flowering is controlled by endogenous cues and environmental factors. Both endogenous and exogenous factors regulate flowering time through different well-characterized pathways. Mounting evidence suggests that environmental cues target the biosynthesis or perception of hormones, which therefore not only orchestrate intrinsic developmental programs, but also convey environmental inputs. In another word, the switch to reproductive development occurs through the induction of floral developmental genes in response to environmental signals such as; light and temperature.

While, [29] reported that many hormones are involved in the regulation of floral developmental genes. They stated that out of the eight principal classes of plant hormones have been characterized: abscisic acid, auxin, brassinosteroids, cytokinins, ethylene, gibberellins, jasmonates and strigolactones; all of them have been linked to growth regulation in one way or another, sometimes in a context-specific manner [30, 31, 32]. As to why plants have evolved multiple hormone response pathways to regulate the same process remains largely a matter of speculation because of a sheer lack of data.

Based on this deep understanding and complexity of floral developmental process and their crosstalk with hormone signalling transduction pathways in dioecious plants; the putative functions of all differential gene hits (generated from SCoT, CDDP and ITAP marker systems) will be addressed, separately, for further and better understanding for their role in floral developmental and sex differentiation processes in date palm trees.

\subsection{The Role of Differentially Targeted-Genes in Plant Development}

\subsubsection{SCoT1: Shikimate O-Hydroxycinnamoyl Transferase-Like (HCT)}

Shikimate pathways provide important precursors for a wide range of important secondary metabolites including chlorogenic acid, alkaloids, glucosinolates, auxin, tannins, suberin, lignin and lignan, tocopherols, and betalains [33].

One of those secondary metabolites was lignin which known to be important for plant secondary cell-wall formation, and lignin biosynthesis and the associated regulatory mechanisms have been studied in the model plant Arabidopsis, various crops, and woody trees [34, 35, 36]. Monolignols of lignin are synthesized via the phenylpropanoid pathway and then oxidatively polymerized to lignin polymers. Hydroxy Cinnamoyl Transferase (HCT) is a recently discovered as a key enzyme in the monolignol-specific pathway. HCT enzyme converts $\rho$-coumaroyl $\mathrm{CoA}$ and caffeoyl $\mathrm{CoA}$ to their corresponding shikimate or quinate esters, and also catalyzes the reverse reaction [37].

In this context, [38] found that observed changes in lignin content are likely to be associated with changes in flowering time. Also, [39] reported that down-regulation of hydroxycinnamoyl CoA: shikimate hydroxycinnamoyl transferase in transgenic alfalfa resulted in greatly reduced lignin content and a delay in flowering. The early flowering phenotype observed in studies of [38, 39] provides the possibility that engineered changes in lignin quantity may allow beneficial changes in reproductive development.

On the other hand, [40] reported that down-regulation of the enzyme hydroxycinnamoyl CoA: shikimate 
hydroxycinnamoyl transferase (HCT) in Arabidopsis thaliana and Medicago sativa leads to strongly reduced lignin levels, reduced recalcitrance of cell walls to sugar release, but severe stunting of the plants. Levels of the stress hormone salicylic acid (SA) are inversely proportional to lignin levels and growth in a series of transgenic alfalfa plants in which lignin biosynthesis has been perturbed at different biosynthetic steps. Also, it was found that repression of HCT resulted in marked changes in the amount and composition of lignin, thus demonstrating that HCT functions in phenylpropanoid metabolism in planta [41]. Moreover, [42] reported that accumulation of polyamine conjugates in the reproductive organs of plants has also been associated with fertility.

\subsubsection{SCoT24: Indole-3-Acetic Acid-Amido Synthetase GH3.8}

Auxin (IAA) known to plays a central role in initiating floral primordia and specifying the number and identity of floral organs, but the mechanism remains unclear [43]. Moreover, Auxin is not only critical for plant embryo development, morphogenesis, polar differentiation and growth, but also has a feminizing effect in spinach and cucumis [44, 45].

In this context, [46] investigated the level of indole-3-acetic acid (IAA) during zygote and embryo development of Nicotiana tabacum L.. They results showed an increase in IAA content in ovules and the polar distribution of IAA, ABP1, and $\mathrm{PM} \mathrm{H}+$-ATPase in the zygote and embryo, specifically in the top and basal parts of the embryo proper (EP) during pro-embryo development. Moreover, they reported that ABP1 and PM H + -ATPase may play roles in zygote and embryo development and may also be involved in IAA signalling transduction.

While, [47] Ding et al., (2008) demonstrated a new evidence suggests a role for the plant growth hormone auxin in pathogenesis and disease resistance. Bacterial infection induces the accumulation of indole-3-acetic acid (IAA), the major type of auxin, in rice (Oryza sativa). IAA induces the expression of expansins, proteins that loosen the cell wall. Loosening the cell wall is key for plant growth but may also make the plant vulnerable to biotic intruders. They reported that rice GH3-8, an auxin-responsive gene functioning in auxin-dependent development, activates disease resistance in a salicylic acid signaling- and jasmonic acid signaling-independent pathway. GH3-8 encodes an IAA-amino synthetase that prevents free IAA accumulation. Indeed, the plant hormone jasmonic acid (JA) is essential for stress responses and the formation of reproductive organs, but its role in fruit development and ripening is unclear.

\subsubsection{SCoT26-1: Cysteine-Rich Repeat Secretory Protein 38-Like}

The genes coding the plant-specific Cys-rich motifs (domain of unknown function26 [DUF26]) make up a large gene family, and the motif was initially found in the extracellular region of cysteine-rich receptor-like kinases (CRKs) and Cys-rich secretory proteins from Arabidopsis. Several CRKs are known to be involved in resistance to bacterial and fungal pathogens, hypersensitive response-related cell death, oxidative stress responses, and salicylic acid-dependent defense pathways [48, 49]. A recent study also showed that some CRKs regulate ABA signaling and osmotic stress responses [50].

In this context, [51] reported that Arabidopsis TSO1 gene which encodes a protein with conserved cysteine-rich repeats was expressed in the floral meristem and floral organs during active cell division. They showed that tso1 mutants displayed defects in cell division of floral meristem cells including partially formed cell walls, increased DNA content, and multinucleated cells. While, [52] reported that one of Cys-rich proteins (LAT52) was known to be essential during pollen hydration and pollen tube growth.

Also, [53] presented results indicate that the leaf-stem-root apoplast continuum in poplar contains diverse proteins that appear to be post-translationally modified and involved in important functions such as cell wall metabolism, stress/defense, and carbohydrate metabolism.

\subsubsection{SCoT26-2: Zinc Finger Protein 1-Like}

Proteins containing zinc finger domain(s) were found to play important roles in eukaryotic cells regulating different signal transduction pathways and controlling processes, such as development and programmed cell death. A complex network of transcription factors orchestrates the response of plants to changes in environmental conditions [54]. These include WRKY and other zinc-finger proteins (72 WRKY genes and more than 600 zinc-finger proteins in Arabidopsis [55]), MYB transcription factors (133 genes in Arabidopsis; [56]), and heat shock transcription factors (21 genes in Arabidopsis; [57]). However, only a few of these transcription factors appear to respond in a similar manner to all or most of the different environmental stress conditions tested in Arabidopsis.

One representative of the small group of genes that responds similarly to many different environmental stress conditions is the zinc-finger protein Zat12 (At5g59820). Zat12 was found to respond at the steady-state transcript level to ozone fumigation; wounding; bacterial, fungal, or nematode infection; $\mathrm{H}_{2} \mathrm{O}_{2}$; heat; cold; drought; elicitor; heavy metal; methanol; fumonisin; or UV application [58, 59, 60].

Indeed, that all Arabidopsis zinc-finger proteins (AZFs) are involved in the water-stress response of Arabidopsis. One of those Arabidopsis zinc-finger proteins, AZF-1 which found to responds rapidly to salt and cold stresses but appears to be abscisic acid (ABA) independent [61].

\subsubsection{SCoT35-1: Trihelix Transcription Factor GTL1-Like}

The GT-2 like 1 (GTL1) trihelix transcription factor found to play an important role as a stomatal development regulatory determinant that controls stomatal density through trans-repression of SDD1 expression [62]. In additions, it have been implicated in other processes, including endoreduplication, petal development, and abiotic stress tolerance in Arabidopsis and soybean (Glycine max; [63, 64, 65]).

In this context, recent study [62] presented a clear evidence that GT-2 LIKE 1 (GTL1) functions as a focal regulator of water stress tolerance and WUE through a mechanism that involves transcriptional repression of SDD1 and regulation of 
stomatal density and transpiration. The GT-2 transcription factor family proteins contain two trihelix DNA binding domains found that interact with GT cis-acting elements (GT elements) during transcriptional regulation. They demonstrated that the GT-2 like 1 (GTL1) trihelix transcription factor is SDD1 encodes a subtilisin-like protease that is implicated to process propeptides into signaling ligands that are negative regulators of stomatal density. They found that Loss-of-function gtll mutations enhance water use efficiency (WUE) and drought tolerance due to a reduced transpiration rate that is correlated with a lowered stomatal density compared to wild-type plants.

\subsubsection{SCoT35-3: Probable Methyl-Transferase PMT28}

Epigenetic mechanisms such as DNA methylation are known to regulate important developmental processes in higher eukaryotes. Methylation is carried out by DNA methyltransferases which catalyse the transfer of a methyl group to bases within the DNA helix. In plants, DNA methylation has been implicated in regulating gene expression patterns [66], cellular differentiation [67], developmental programs [68, 69] and genome stability [70]. It also controls the transcription of invading and mobile DNA elements, such as transgenes, viruses, transposons and retro-elements [71].

In plants, there are mounting evidence indicates that DNA methylation plays critical roles in regulating gene expression in a tissue-specific or developmental stage-dependent manner across plant development [72, 73].

Recent study [74] aimed to understanding the biological roles of DNA methylation have involved global changes in methylation patterns by using the methyltransferase (MTase) inhibitor zebularine, it is observed that various aspects of growth and differentiation during gametophyte development become aberrant. Moreover, [75] examined the DNA methylation levels in male and female floral organs and found that DNA methylation level in females was higher than in males. This significant decreasing of DNA methylation levels in male flowers, suggesting that DNA demethylation might be another driving force for male flower development progression, which occurs earlier than female flower development. These results provide primary DNA methylation level clues regarding the difference between female and male flower development.

\subsubsection{SCoT35-5: Probable WRKY Transcription Factor 65}

In higher plants, the WRKY gene family members play a variety of roles. Accumulating evidence indicates that WRKY transcription factors are involved in responses to environmental stimuli, such as high salt, drought, heat, cold and other abiotic stresses. They play an important regulatory role in anti-viral, anti-bacterial, mechanical injury pathways, and nutrient deprivation, senescence, seed and trichome development, embryogenesis, as well as additional developmental and hormone-controlled processes; showing that WRKY transcription factors have a complex and important role in regulation [76].

In this context, [77] stated that WRKY65 play an important role in sugar sensing and metabolism in Arabidopsis. They reported that both WRKY65 and WRKY45 are involved in regulating genes which respond to carbon starvation.

\subsubsection{CDDP4: Ethylene-Responsive Transcription Factor 4-Like}

Ethylene Responsive Factors (ERFs) are plant specific transcription factors, which play an important role in a variety of biological processes like development, biotic and abiotic stress responses. They can act as activators or repressors of the expression of stress responsive genes in stress signal transduction pathways. Most of the information about the role played by ERFs comes from studies based on loss of function, overexpression of ERFs and their respective affects $n$ the plant phenotype and gene expression analysis at a particular stress or developmental stage of the plant. The same ERF can act in response to different stresses through same or different signaling pathways leading to functional redundancy of ERFs. In addition to this there are sets of genes, which respond to multiple stresses making it even more difficult to predict the exact role of ERFs [78].

The ERF family of genes encodes plant specific transcription factors that are characterized by the presence of a highly conserved AP2/ERF domain of sixty to seventy amino acids. These transcription factors play important roles in a variety of biological processes in plants such as development, abiotic and biotic stress responses [79, 80]. The AP2 domain was first characterized in APETALA protein, which is involved in flower development [81]. In particular, AtERF4 was found to negatively regulate disease resistance and JA-dependent expression of PDF1.2 [82].

In this context, [83] reported that overexpression of an ERF gene from Brassica rapa ssp. Pekinensis (BrERF4) led to improved tolerance to salt and drought stresses in Arabidopsis. It also significantly affected the growth and development of transgenic plants. While, [84] reported that Arabidopsis genome contains eight ERF repressors, namely AtERF3, AtERF4, and AtERF7 to AtERF12. Members of ERF repressors show differential expression, suggesting that they may have different function. They demonstrated by using a transient expression system, that AtERF4, AtERF7, AtERF10, AtERF11 and AtERF12 can function as transcriptional repressors. The expression of AtERF4 can be induced by ethylene, jasmonic acid, and abscisic acid (ABA). They study provides evidence that AtERF4 is a negative regulator capable of modulating ethylene and abscisic acid responses. In general, they demonstrated that the AtERF4 can act as a transcriptional repressor to repress GCC-box-mediated gene transcription.

\subsubsection{CDDP6-1: Phosphoenolpyruvate/Phosphate Translocator- 1 (PPT1)}

Communication between plastids and the surrounding cytosol occurs via the plastid envelope membrane. The inner envelope membrane contains a variety of transporters that mediate the exchange of metabolites between both compartments. Most organelles require the import of phosphoenolpyruvate as an immediate substrate for carbon to enter the shikimate pathway, leading to a variety of important secondary compounds. The envelope membrane of plastids contains specific translocators that are involved in these 
transport processes [85].

The physiological function of PPT in plants is to supply plastidic metabolism with PEP, which can be used as a substrate for the shikimate pathway. In all types of plastids, PEP serves different functions, e.g. as precursor for the biosynthesis of fatty acids or of aromatic amino acids. PEP is an immediate substrate for the plastid-localized shikimate pathway leading, via the synthesis of aromatic amino acids, to a large number of secondary metabolites, e.g. alkaloids, flavonoids, and lignins [86].

In this regards, [87] presented a study titled: Phosphoenolpyruvate Provision to Plastids Is Essential for Gametophyte and Sporophyte Development in Arabidopsis thaliana. They found that restriction of phosphoenolpyruvate (PEP) supply to plastids causes lethality of female and male gametophytes in Arabidopsis thaliana defective in both a phosphoenolpyruvate/phosphate translocator (PPT) of the inner envelope membrane and the plastid-localized enolase (ENO1) involved in glycolytic PEP provision. They speculated that, at least in the female gametophytes PEP, after conversion to pyruvate, serves as the major substrate for fatty acid biosynthesis and consequently, the diminished fatty acid provision may lead to a halt in ovule development in ccEe plants similar to the heterozygous gpt1 mutant developed by [88].

\subsubsection{CDDP6-2: Regulatory Protein NPR 1-Like}

NON-EXPRESSOR OF PR1 (NPR1) is a transcription co-activator that plays a central role in regulating the transcriptional response to plant pathogens $[89,90,91]$. The NPR family consists of NPR1and five NPR1-likegenes. The NPR1 paralog NPR3 has recently been shown to function as a receptor of the plant hormone salicylic acid and to mediate proteosomal degradation of NPR1. In Arabidopsis, NPR1 is required for the activation or down-regulation of 2248 genes in response to treatment with salicylic acid (SA) analog, BTH [92].

Moreover, [93] reported that NPR3 expression was strongest in the petals and sepals of developing flowers and declined after flower opening. Furthermore, they found that npr1 mutants exhibit reduced expression of defense response genes and increased susceptibility to pathogens. They found that NPR3 is a negative regulator of defense responses during early flower development and it may function through the association with both NPR1 and TGA2.

\subsubsection{ITAP-8/1: Eukaryotic Translation Initiation Factor 4E-1-like}

One of the most regulated steps of translation initiation is the recruitment of mRNA by the translation machinery. In eukaryotes, this step is mediated by the 59 end cap-binding factor eIF4E bound to the bridge protein eIF4G and forming the eIF4F complex. In plants, different isoforms of eIF4E and eIF4G form the antigenically distinct eIF4F and eIF(iso)4F complexes proposed to mediate selective translation [94].

In Arabidopsis, the eIF(iso)4E transcript and protein are more abundant in roots, floral organs and tissues under development $[95,96]$. In maize, the eIF(iso)4E protein is present at higher levels than eIF4E in non-germinated seeds [97]. The corresponding transcript is efficiently translated upon imbibition to maintain constant and high levels during the first $24 \mathrm{~h}$ of germination, whereas eIF4E levels increase toward germination completion [98].

\subsection{Results Explanation and Sex Differentiation Hypothesis}

To date, sex-determining mechanism is still uncertain and there is no reliable way to determine the sex of date palm plants before reproductive age.

Based on the obtained results in this study, we speculate that those medium to high similarity of the sex-specific generated markers with; mainly; plant hormone genes, master transcription factors, transcriptional activators/repressors and regulatory proteins involved in plant hormone signal transduction pathways, floral plant development and biosynthesis of secondary metabolites, is not just a coincidence. We hypothesis that sex differentiation is a complex but well-organized process that involves endogenous and exogenous factors regulate the changes in gene expression, physiology, metabolism and architecture of the plant.

With regard to endogenous factors regulating the sex differentiation process; due to their level of complexity and our deep understanding of reproductive development in plant, the old suggestion by [99] that genetic sex determination occurs through a single locus became illogical as point of view.

On the other side, daily, there are mounting evidence suggests that exogenous factors (environmental signals such as; light and temperature,... etc.) targets the biosynthesis of TFs, secondary metabolites and hormones which not only orchestrate intrinsic developmental programs, but also handles the environmental stresses and their tolerance.

\section{Acknowledgements}

This research project was carried out in Agricultural Genetic Engineering Research Institute and funded by the Science and Technological Development Fund (STDF) under the program of U.S. - Egypt Joint Board on Scientific and Technological Cooperation, Contract No. 4607 titled "Germplasm conservation, genetic characterization, next-generation sequencing, and molecular markers and bioinformatics analysis to distinguish the genders of date palm trees".

\section{References}

[1] Wrigley, G. (1995). "Date palm. In: Smartt J, Simmonds NW (Ed) Evolution of crop plants", 2nd edn. Longman Group, Essex, England.

[2] Wellmann, A.P., Escobar, A.H., Johnson, D.V. (2007). Date palm cultivation in Chile and Peru (South America): current status and future prospects for development. Acta Hort., 736: 71-85.

[3] Kurup, S.S., Hedar, Y.S., Al Dhaheri, M.A., El-Heawiety, A.Y., Aly, M.A.M., Alhadram, G. (2009). Morpho-physiological evaluation and RAPD markers-assisted characterization of date palm (Phoenix dactylifera L.) varieties of salinity tolerance. J. Food Agric. Environ., 7: 503-507. 
[4] FAOstat, 2012.

[5] Aberlenc-Bertossi, F., Daher, A., Chabrillange, N., Tregear, J. W., Mohamed, N. (2011). Sex determination in date palm: new perspectives on an old theme. Plant and animal genomes XIX conference, W519: sex chromosomes and sex determination, January 15-19, 2011. Town and Country Convention Center, San Diego, CA

[6] Bounaga, N. (1993). Le palmier dattier: rappels biologiques et problèmes physiologiques. In: Physiologie des arbres et des arbustes en zones arides et semi-arides. Libbey Eurotext, Paris, pp 323-333.

[7] Torres, A. M., Tisserat, B. (1980). Leaf isozymes as genetic marker in date palm. Amer. J. Bot., 67:162-167.

[8] Majourhat, K., Bendiab, K., Medraoui, L., Baaziz, M. (2002). Diversity of leaf peroxidases in date palm (Phoenix dactylifera L.) as revealed in an example of marginal (seedling derived) palm groves. Sci. Hortic., 95: 31-38.

[9] Younis, R. A., Ismail, O. M., Soliman, S. S. (2008). Identification of sex-specific DNA markers for date palm (Phoenix dactylifera L.) using RAPD and ISSR techniques. Research Journal of Agriculture and Biological Sciences, 4: $278-284$.

[10] Ageez, A., E. A. Madboly. (2011). Identification of male specific molecular markers in date palm Sewi cultivar. Egypt. J. Genet. Cytol. 40:201-214.

[11] Al-Mahmoud, M.E., Al-Dous, E.K., Al-Azwani, E.K., Malek, J.A. (2012). DNA-based assays to distinguish date palm (Arecaceae) gender. American Journal of Botany,. 99:7-10.

[12] Cherif, E., et al., (2013). Male-specific DNA markers provide genetic evidence of an XY chromosome system, a recombination arrest and allow the tracing of paternal lineages in date palm. New Phytologist, 197: 409-415.

[13] Adawy, S.S., Jiang, J., Atia, M.A.M. (2014). Identification of novel sex-specific PCR-Based markers to distinguish the genders in Egyptian date palm trees. International Journal of Agricultural Science and Research (IJASR), 4 (5), 45-54.

[14] Collard, B.C., Mackill, D.J. (2009b). Conserved DNA-Derived Polymorphism (CDDP): A Simple and Novel Method for Generating DNA Markers in Plants. Plant Molecular Biology Reports, 27: 558-562.

[15] Xiong, F., Liu, J., Zhong, R., Jiang, J., Han, Z., He, L., Zhong, L., Tang, X., Tang R. (2013). Intron targeted amplified polymorphism (ITAP), a new sequence related amplified polymorphism-based technique for generating molecular markers in higher plant species. Plant Omics Journal, 6(2): 128-134.

[16] Vos, P., Hogers, R., Bleeker, M., Reijans, M., van de Lee, T., Hornes, M., Frijters, A., Pot, J., Peleman, J., Kuiper, M., Zabeau, M. (1995). AFLP: a new technique for DNA fingerprinting. Nucleic Acids Research, 23(21): 4407-4414.

[17] Abd El-Maksoud, M.R., Ageez, A. M. El-Khishin, D. A., Fahmy, E. M., Abdel-Tawab, F. M. (2009). Differential gene expression in response to salt stress in Vicia monantha. Egypt. J. Genet. Cytol., 38:137-152.

[18] Larkin, M. A., Blackshields, G.., Brown, N. P., Chenna, R., Mc Gettigan, P. A., McWilliam, H., Valentin, F., Wallace, I. M., Wilm, A., Lopez, R., Thompson, J. D., Gibson, T. J., Higgins,
D.G. (2007). Clustal $\mathrm{W}$ and ClustalX version 2.0. Bioinformatics, 23 (21): 2947-2948.

[19] Altschul, S. F., Gish, W., Miller, W., Myers, E.W., Lipman, D. J. (1990). Basic local alignment search tool. J. Mol. Biol., 215, 403-410.

[20] Bekheet, S.A., Hanafy, M. S. (2011).Towards sex determination of date palm. Date Palm Biotechnology. New York, NY, USA: Springer.

[21] Adawy, S. S., Atia, M. A. M., El-Itriby, H. A. (2015). Sex-Differentiation Based on Fluorescence In Situ Hybridization (FISH) with 5S and 45S rDNA of Egyptian Date Palm Trees. Int. J. of Adv. Biotech. and Res., 6: 2, 144-151.

[22] Eivazi, A.R., Naghavi, M.R., Hajheidari, M., Pirseyedi, S.M., Ghaffari, M.R., Mohammadi, S.A., Majidi, I., Salekdeh, G.H., Maradi, M. (2008). Assessing wheat (Triticum aestivum L.) genetic diversity using quality traits, amplified fragment length polymorphisms, simple sequence repeats and proteome analysis. Annals of Applied Biology, 152, 81-91.

[23] Raji, A.A.J., Fawole, I., Gedil, M., Dixon, A.G.O. (2009). Genetic differentiation analysis of African cassava (Manihot esculenta) landraces and elite germplasm using amplified fragment length polymorphism and sample sequence repeat markers. Annals of Applied Biology, 155,187-199.

[24] Poczai, P., Cern'ak, I., Gorji, A.M., Nagy, S., Taller, J., Polg'ar Z. (2010). Development of intron targeting (IT) markers for potato and cross-species amplification in Solanum nigrum (Solanaceae). American Journal of Botany, 97, e142-e145.

[25] Poczai, P., Varga, I., Bell, N.E., Hyvönen, J. (2011). Genetic diversity assessment of bittersweet (Solanum dulcamara, Solanaceae) germplasm using conserved DNA-derived polymorphism and intron-targeting markers. Ann. Appl. Biol., 159:141-153.

[26] Bernier, G., Périlleux, C. (2005). A physiological overview of the genetics of flowering time control. Plant Biotechnol. J., 3, $3-16$

[27] Cary, A.J., Che, P., Howell, S.H. (2002). Developmental events and shoot apical meristem gene expression patterns during shoot development in Arabidopsis thaliana. Plant J., 32, 867-877.

[28] Jacqmard, A., Gadisseur, I., Bernier, G. (2003). Cell division and morphological changes in the shoot apex of Arabidopsis thaliana during floral transition. Ann. Bot., 91, 571-576.

[29] Golenberg, E.M., West, N.W. (2013). Hormonal interactions and gene regulation can link monoecy and environmental plasticity to the evolution of dioecy in plants. Am. J. Bot, 100:1022-1037.

[30] Santner, A., Calderon-Villalobos, L.I., Estelle, M. (2009). Plant hormones are versatile chemical regulators of plant growth. Nat. Chem. Biol.5, 301-307.

[31] Wolters, H., Jurgens, G. (2009). Survival of the flexible: hormonal growth control and adaptation in plant development. Nat. Rev. Genet., 10, 305-317.

[32] Santner, A., Estelle, M. (2009). Recent advances and emerging trends in plant hormone signalling. Nature, 459, 1071-1078. 
[33] Tohge, T., Watanabe, M., Hoefgen, R., Fernie, R.A. (2013). Shikimate and phenylalanine biosynthesis in the green lineage. Frontiers in Plant Science, 4, 62:1-13.

[34] Zhong, R., Ye, Z.H. (2009). Transcriptional regulation of lignin biosynthesis. Plant Signaling \& Behavior., 4, 1028-1034.

[35] Zhao, Q., Dixon, R.A. (2011). Transcriptional networks for lignin biosynthesis: more complex than we thought? Trends in Plant Science, 16, 227-233.

[36] Vanholme, R., Demedts, B., Morreel, K., Ralph, J., Boerjan, W. (2010). Lignin biosynthesis and structure. Plant Physiology, 153, 895-905.

[37] Hoffmann, L., Besseau, S., Geoffroy, P., Ritzenthaler, C., Meyer, D., Lapierre, C., Pollet, B., Egrand, M. (2004). Silencing of hydroxycinnamoyl-Coenzyme A shikimate/quinate hydroxycinnamoyl- transferase affects phenylpropanoid biosynthesis. Plant Cell, 16:1446-1465.

[38] Wang, Y.W., Wang, W.C., Jin, S.H., Wang, J., Wang, B., Hou, B.K. (2012). Over-expression of a putative poplar glycosyltransferase gene, PtGT1, in tobacco increases lignin content and causes early flowering. J. Exp. Bot., 63(7):2799-2808.

[39] Shadle, G., Chen, F., Srinivasa, Reddy, M.S., Jackson, L., Nakashima, J., Dixon, R.A. (2007). Down-regulation of hydroxycinnamoyl CoA: shikimate hydroxycinnamoyl transferase in transgenic alfalfa affects lignification, development and forage quality. Phytochemistry, 68, 1521-1529.

[40] Gallego-Giraldo, L., Escamilla-Trevino, L., Jackson, L. A., Dixon, R. A. (2011). Salicylic acid mediates the reduced growth of lignin down-regulated plants. PNAS, 108, 51: 20814-20819.

[41] Besseau S., Hoffmann L., Geoffroy P., Lapierre C., Pollet B. and Legrand M. (2007). Flavonoid Accumulation in Arabidopsis Repressed in Lignin Synthesis Affects Auxin Transport and Plant Growth. The Plant Cell, Vol. 19: 148-162.

[42] Martin-Tanguy, J., Perdrizet, E., Prevost, J., Martin, C. (1982). The distribution of hydroxycinnamic acid amides in fertile and cytoplasmic male sterile lines of maize. Phytochemistry, 21, 1939-1945.

[43] Cecchetti, V., Altamura, M.M., Falasca, G., Costantino, P., Cardarelli, M. (2008). Auxin regulates Arabidopsis anther dehiscence, pollenmaturation, and filament elongation. Plant Cell, 20:1760-1774.

[44] Ni, W.M., Chen, X.Y., Xu, Z.H., Xue, H.W. (2002). A Pin gene families encoding components of auxin efflux carriers in Brassica juncea. Cell Res., 12:247-255.

[45] Malepszy, S., Niemirowicz-szczytt, K. (1991). Sex determination in cucumber (Cucumis sativus) as a model system for molecular biology. Plant Sci., 80:39-47.

[46] Chen, D., Ren, Y., Deng, Y., Zhao, J. (2010). Auxin polar transport is essential for the development of zygote and embryo in Nicotiana tabacum L. and correlated with ABP1 and PM H+ -ATPase activities. Journal of Experimental Botany, 61: 6, 1853-1867.

[47] Ding, X., Cao, Y., Huang, L., Zhao, J., Xu, C., Li, X., Wang, S. (2008). Activation of the Indole-3-Acetic Acid-Amido Synthetase GH3-8 Suppresses Expansin Expression and
Promotes Salicylate- and Jasmonate-Independent Basal Immunity in Rice. The Plant Cell, 20: 228-240.

[48] Wrzaczek, M., Brosché, M., Salojärvi, J., Kangasjärvi, S., Idänheimo, N., Mersmann, S., Robatzek, S., Karpinski, S., Karpinska, B., Kangasjärvi, J. (2010). Transcriptional regulation of the CRK/DUF26 group of receptor like protein kinases by ozone and plant hormones in Arabidopsis. BMC Plant Biol10:95.

[49] Rayapuram, C., Jensen, M.K., Maiser, F., Shanir, J.V., Hornshøj, H., Rung, J.H., Gregersen, P.L., Schweizer, P., Collinge, D.B., Lyngkjær, M.F. (2012). Regulation of basal resistance by a powdery mildew-induced cysteine-rich receptor-like protein kinase in barley. Mol. Plant Pathol., 13:135-147.

[50] Tanaka, H., Osakabe, Y., Katsura, S., Mizuno, S., Maruyama, K., Kusakabe, K., Mizoi, J., Shinozaki, K., Yamaguchi-Shinozaki, K. (2012). Abiotic stress inducible receptor-like kinases negatively control ABA signaling in Arabidopsis. Plant J., 70:599-613.

[51] Song, J., Leung, T., Linda, K., Wang, C., Liu Z. (2000). Regulation of meristem organization and cell division by TSO1, an Arabidopsis gene with cysteine-rich repeats. Development, $127,2207-2217$.

[52] Tang, W., Ezcurra, I., Muschietti, J., McCormick, S. (2002). A Cysteine-Rich Extracellular Protein, LAT52, Interacts with the Extracellular Domain of the Pollen Receptor Kinase LePRK2. The Plant Cell, 14, 2277-2287.

[53] Pechanova, et al., (2010). Apoplast proteome reveals that extracellular matrix contributes to multistress response in poplar BMC Genomics, 11:674.

[54] Chen, W., Provart, N.J., Glazebrook, J., Katagiri, F., Chang, H.S., Eulgem, T., Mauch, F., Luan, S., Zou, G., Whitham, S.A., et al., (2002). Expression profile matrix of Arabidopsis transcription factor genes suggests their putative functions in response to environmental stresses. Plant Cell, 14: 559-574.

[55] Eulgem, T., Rushton, P.J., Robatzek, S., Somssich, I.E. (2000). The WRKY superfamily of plant transcription factors. Trends Plant Sci., 5:199-206.

[56] Stracke, R., Werber, M., Weisshaar, B. (2001). The R2R3-MYB gene family in Arabidopsis thaliana. Curr. Opin. Plant Biol., 4:447-456.

[57] Nover, L., Bharti, K., Doring, P., Mishra, S.K., Ganguli, A., Scharf, K.D. (2001). Arabidopsis and the heat stress transcription factor world: How many heat stress transcription factors do we need? Cell Stress Chaperones, 6: 177-189.

[58] Cheong, Y.H., Chang, H.S., Gupta, R., Wang, X., Zhu, T., Luan, S. (2002). Transcriptional profiling reveals novel interactions between wounding, pathogen, abiotic stress, and hormonal responses in Arabidopsis. Plant Physiol., 129:661-677.

[59] Rizhsky, L., Davletova, S., Liang, H., Mittler, R. (2004). The zinc-finger protein Zat12 is required for cytosolic ascorbate peroxidase 1 expression during oxidative stress in Arabidopsis. J. Biol. Chem., 279:11736-11743.

[60] Davletova, S., Rizhsky, L., Liang, H., Shengqiang, Z., Oliver, D.J., Coutu, J., Shulaev, V., Schlauch, K., Mittler, R. (2005). Cytosolic ascorbate peroxidase 1 is a central component of the reactive oxygen gene network of Arabidopsis. Plant Cell, $17: 268-281$. 
[61] Sakamoto, H., Maruyama, K., Sakuma, Y., Meshi, T., Iwabuchi, M., Shinozaki, K., Yamaguchi-Shinozaki, K. (2004). ArabidopsisCys2/His2-type zinc-finger proteins function as transcription repressors under drought, cold, and high-salinity stress conditions. Plant Physiol., 136, 2734 - 2746.

[62] Yoo, C.Y., Pence, H.E., Jin, J.B., Miura, K., Gosney, M.J., et al., (2010) The Arabidopsis GTL1 transcription factor regulates water use efficiency and drought tolerance by modulating stomatal density via trans-repression of SDD1. Plant Cell, 22: $4128-4141$

[63] Brewer, P.B., Howles, P.A., Dorian, K., Griffith, M.E., Ishida, T., Kaplan-Levy, R.N., Kilinc, A., Smyth, D.R. (2004). PETAL LOSS, a trihelix transcription factor gene, regulates perianth architecture in the Arabidopsis flower. Development, 131:4035-4045.

[64] Breuer, C., Kawamura, A., Ichikawa, T., Tominaga-Wada, R., Wada, T., Kondou, Y., Muto, S., Matsui, M., Sugimoto, K. (2009). The trihelix transcription factor GTL1 regulates ploidy-dependent cell growth in the Arabidopsis trichome. Plant Cell, 21:2307-2322.

[65] Xie, Z.M., Zou, H.F., Lei, G., Wei, W., Zhou, Q.Y., Niu, C.F., Liao, Y., Tian, A.G., Ma, B., Zhang, W.K., Zhang, J.S., Chen, S.Y. (2009). Soybean Trihelix transcription factors GmGT-2A and GmGT-2B improve plant tolerance to abiotic stresses in transgenic Arabidopsis. PLoS ONE, 4:e6898.

[66] Finnegan, E.J., Peacock, W.J., Dennis, E.S. (1996). Reduced DNA methylation in Arabidopsis thaliana results in abnormal plant development. Proc. Natl. Acad. Sci. USA, 93, $8449-8454$.

[67] Kingham, K.I., Duckett, J.G., Gazdova, B., Kovarik, A., Bezdek, M., Leitch, A.R. (1998). The role of DNA methylation on nuclear and cell differentiation in the filamentous caulonema of the moss Funaria hygrometrica. New Phytol., $138,567-577$.

[68] Ronemus, M.J., Galbiati, M., Ticknor, C., Chen, J., Dellaporta, S.L. (1996) Demethylation-induced developmental pleiotropy in Arabidopsis. Science, 273, 654-657.

[69] Iwase, Y., Shiraya, T., Takeno, K. (2010). Flowering and dwarfism induced by DNA demethylation in Pharbitis nil. Physiol. Plant, 139, 118-127.

[70] Kidwell, M.G., Lisch, D.R. (2001). Perspective: transposable elements, parasitic DNA, and genome evolution. Evolution, 55, $1-24$.

[71] Bird, A. (2002). DNA methylation patterns and epigenetic memory. Genes Dev., 16, 6-21.

[72] Chan, S.W.L., Henderson, I.R., Jacobsen, S.E. (2005). Gardening the genome: DNA methylation in Arabidopsis thaliana. Nat. Rev. Genet., 6: 351-360.

[73] Gehring, M., Henikoff, S. (2007). DNA methylation dynamics in plant genomes. Biochim. Biophys. Acta, 1769: 276-286.

[74] Garima, M., Meenakshi, D., Sanjay, K., Meenu, K., (2012). Role of DNA methylation in growth and differentiation in Physcomitrella patens and characterization of cytosine DNA methyltransferases. FEBS Journal, 279, 4081-4094.

[75] Song, Y., Ma, K., Ci, D., Chen, Q., Tian, J., Zhang, D., (2013). Sexual dimorphic floral development in dioecious plants revealed by transcriptome, phytohormone, and DNA methylation analysis in Populus tomentosa. Plant Mol Biol., DOI 10.1007/s11103-013-0108-2.

[76] Ishihama, N., Yamada, R. et al., (2011). Phosphorylation of the Nicotiana benthamiana WRKY8 transcription factor by MAPK functions in the defense response. Plant Cell, 23:1153-70.

[77] Contento, A.L., Kim, S.J., Bassham, D.C. (2004). Transcriptome profiling of the response of Arabidopsis suspension culture cells to Suc starvation. Plant Physiol., 135:2330-47.

[78] Manali, M., Ritika, D., Girdhar, K. P. (2009). Role of Ethylene Responsive Factors (ERFs) in Abiotic Stress Mediated Signaling in Plants. Journal of Biological Sciences, 1, Issue 1, 133-146.

[79] Chuck, G., Muszynski, M., Kellogg, E., Hake, S., Schmidt, R.J. (2002). The control of spikelet meristem identity by the branched silkless1 gene in maize. Science, 298, 1238-1241.

[80] Park, J.M., Park, C.J., Lee, S.B., Ham, B.K., Shin, R., Paek, K.H. (2001). Overexpression of the Tobacco Tsil gene encoding an EREBP/AP2 Type transcription factor enhances resistance against pathogen attack and osmotic stress in Tobacco", The Plant Cell, 13, 1035-1046.

[81] Jofuku, K.D., den Boer, B.G., Van Montagu M., Okamuro, J.K. (1994). Control of Arabidopsis flower and seed development by the homeotic gene APETALA2. Plant Cell, 6, 1211-1225.

[82] McGrath, K.C., Dombrecht, B., Manners, J.M., Schenk, P.M., Edgar, C.I., Maclean, D.J., Scheible, W.R., Udvardi, M.K., Kazan, K. (2005). Repressor- and activator-type ethylene response factors functioning in jasmonate signaling and disease resistance identified via a genome-wide screen of Arabidopsis transcription factor gene expression. Plant Physiol., 139, 949-959.

[83] Seo, Y. J., et al., (2010). Overexpression of the Ethylene-Responsive Factor Gene BrERF4 from Brassica rapa Increases Tolerance to Salt and Drought in Arabidopsis Plants. Mol. Cells, 30, 271-277.

[84] Yang, Z., Tian, L., Latoszek-Green, M., Brown, D., Wu, K. (2005). Arabidopsis ERF4 is a transcriptional repressor capable of modulating ethylene and abscisic acid responses. Plant Molecular Biology, 58:585-596.

[85] Fl"ugge, U.I., Heldt, H.W. (1991). Metabolite translocators of the chloroplast envelope. Annu. Rev. Plant Physiol., 42:129-44.

[86] Voll, L., Häusler, R.E., Hecker, R., Weber, A., Weissenböck, G., Fiene, G., Waffenschmidt, S., Flügge, U.I. (2003). The phenotype of the Arabidopsis cue1 mutant is not simply caused by a general restriction of the shikimate pathway. Plant J., 36, 301-316.

[87] Prabhakar, V., Lo"ttgert, T., Gigolashvili, T., Bell, K., Flu“gge, U.I., and Ha"usler, R.E.(2009). Molecular and functional characterization of the plastid-localized phosphoenolpyruvate enolase ENO1 from Arabidopsis thaliana. FEBS Lett., 583:983-991.

[88] Niewiadomski, P., Knappe, S., Geimer, S., Fischer, K., Schulz, B., Unte, U.S., Rosso, M.G., Ache, P., Flu"gge, U.I., Schneider, A. (2005). The Arabidopsis plastidic glucose 6-phosphate/phosphate translocator GPT1 is essential for pollen maturation and embryo sac development. Plant Cell, 17:760-775. 
[89] Shi, Z., Maximova, S.N., Liu, Y., Verica, J., Guiltinan, M.J. (2010). Functional analysis of the Theobroma cacao NPR1 gene in Arabidopsis. BMC Plant Biol., 10,248.

[90] Maier, F., et al. (2011). NONEXPRESSOR OF PATHOGENESIS-RELATED PROTEINS1 (NPR1) and some NPR1-related proteins are sensitive to salicylic acid. Mol. Plant Pathol., 12, 73-91.

[91] Xiao, S., Chye, M.L. (2011). Overexpression of Arabidopsis ACBP3 enhances NPR1-dependent plant resistance to Pseudomonas syringe pv tomato DC3000. Plant Physiol., 156, 2069-2081.

[92] Wang, D., Amornsiripanitch, N., Dong, X. (2006). A genomic approach to identify regulatory nodes in the transcriptional network of systemic acquired resistance in plants. PLoS Pathog., 2, e123.

[93] Shi, Z., Maximova, S., Liu, Y., Verica, J., Guiltinan M.J. (2013) The Salicylic Acid Receptor NPR3 Is a Negative Regulator of the Transcriptional Defense Response during Early Flower Development in Arabidopsis. Molecular Plant, 6, 3 : 802-816.

[94] Mart1'nez-Silva, A.V., Aguirre-Martı'nez, C., Flores-Tinoco, C.E., Alejandri-Ramı'rez, N.D., Dinkova, T.D. (2012).
Translation Initiation Factor AteIF(iso)4E Is Involved in Selective mRNA Translation in Arabidopsis thaliana Seedlings. PLoS ONE, 7(2): e31606. doi:10.1371/journal.pone.0031606.

[95] Rodriguez, C.M., Freire, M.A., Camilleri, C., Robaglia, C. (1998). The Arabidopsis thaliana cDNAs coding for eIF4E and eIF(iso)4E are not functionally equivalent for yeast complementation and are differentially expressed during plant development. Plant J., 13: 465-473.

[96] Bush, M.S., Hutchins, A.P., Jones, A.M., Naldrett, M.J., Jarmolowski, A., et al., (2009). Selective recruitment of proteins to 59cap complexes during the growth cycle in Arabidopsis. Plant J., 59: 400-412.

[97] Dinkova, T.D., Sanchez de Jimenez, E. (1999). Differential expression and regulation of translation initiation factors $-4 \mathrm{E}$ and -iso4E during maize germination. Physiol. Plant, 107: 419-425.

[98] Dinkova, T.D., Aguilar, R., Sanchez de Jimenez, E. (2000). Expression of maize eukaryotic initiation factor (eIF) iso4E is regulated at the translational level. Biochem. J., 351: 825-831.

[99] Saadi, M. (1990). Amelioration genetique du palmier dattier: Criteres de selection, techniques et resultats. Options Mediterraneennes, 11: 133-134. 